LIBRO

Patricia Arancibia Clavel y Francisco Balart:

Sergio de Castro, el Arquitecto del Modelo Económico Chileno

(Santiago: Biblioteca Americana, 2007).

\title{
MODERNIZACIÓN, DESARROLLO, DICTADURA: EL PAPEL DE SERGIO DE CASTRO
}

\author{
Joaquín Fermandois
}

Еl “modelo chileno", admirado, vitoreado, escarnecido o simplemente mirado con un dejo de escepticismo, ha llegado a ser una especie de marca registrada en el continente y más allá de él. Identifica al Chile actual, y gran parte de los debates públicos giran directa o indirectamente en torno a él. En los años noventa hasta desde las filas de los gobiernos concertacionistas salían palabras de elogio a las reformas impulsadas por el régimen militar y su equipo de asesores económicos.

En la década del 2000 el reconocimiento de estos hechos ha experimentado una audaz transformación. La Concertación, asumida la herencia del "régimen de Pinochet" en la estrategia económica, ha podido beber una leche de pecho de gran rendimiento y con ello mostrar a este modelo como suyo. El verdadero progreso no podría tener un origen pecaminoso, sino que era resultado de haber dado un contenido social a una política económica que, por lo demás, no había rendido demasiados frutos. Con la vuelta de mano político-cultural que se ha producido desde aproximadamente el 2000, cada día más observadores tienden a aceptar esta visión. Tiene un viso de verosimilitud por el hecho de que el promedio del crecimiento entre 1973 y 1990 es claramente inferior al que ha habido entre 1990 y 2007.

JoAquín Fermandois. Profesor de historia contemporánea, Pontificia Universidad Católica de Chile; miembro de número de la Academia Chilena de la Historia.

Estudios Públicos, 108 (primavera 2007). 
Entonces, ¿̇por qué cada día más políticos e intelectuales de la Concertación comienzan a desesperar del "modelo" y piden a gritos "correcciones"? Porque existen realidades duras, que pueden alojarse en una suerte de pre-consciente desde donde las percibimos. Y ellas nos indican que todo lo que se ha construido en lo económico y social se originó en un proyecto que tuvo su puntapié inicial a fines de abril de 1975 con el discurso de Jorge Cauas anunciando lo que ya antes se le denominaba plan de "shock". El motor individual más perfilado y sistemático de este proyecto fue Sergio de Castro. También, el bochorno oculto que produce esto en la Concertación no es sólo producto de la anciana práctica política de adjudicarse todos los logros y no responsabilizarse por ninguno de los yerros. La madre del cordero se encuentra en que su ejecución hubiera sido imposible sin la existencia del gobierno militar y, más aun, dentro de él su principal soporte fue el liderato de Pinochet, quizás como una herramienta para perfilar mejor su proyecto personalista. Este libro nos revela una parte sustancial de esa historia.

\section{La validez de una historia testimonial}

La obra de Patricia Arancibia y Francisco Balart consiste en lo fundamental en una columna vertebral constituida por una serie de entrevistas con el ex ministro Sergio de Castro. Escrito en tercera persona, aunque siempre refiriéndose a "Sergio", los párrafos textuales de De Castro ocupan un espacio mayor en el libro, quizás una cuarta parte de él. El resto es tanto el parafraseo de los autores como la intercalación de otras opiniones de economistas cercanos o lejanos a De Castro, con algo de otros líderes y actores del Estado principalmente de los años del gobierno militar. Se añade también ocasionalmente un contexto histórico relativamente limitado.

Este libro es así otro eslabón de la trayectoria de Patricia Arancibia con diversos coautores. La historiadora se ha caracterizado por una labor historiográfica relacionada con un reportaje de nivel destacado que tiene grandes antecedentes en el mundo cultural anglosajón, pero que ha sido escaso en Chile, entre otras razones por la reticencia de los historiadores a eso de relacionarse mucho con el mundo del periodismo. La autora es parte de una generación de historiadores que ha comenzado a llevar el argumento histórico (¿qué nos enseña el pasado?) al debate público, con los riesgos que esto implica de exponer razonamientos esquemáticos acerca de problemas que los historiadores saben perfectamente que no pueden ser definidos de un modo exacto por una teoría explicativa. Con todo, este tipo de trabajo viene a aportar otro ángulo en este proceso mediante el cual la historia 
contemporánea de Chile se está convirtiendo cada día más en legitimación de los proyectos acerca del “deber ser” de la sociedad. Es parte de la batalla por una "hegemonía cultural” que caracteriza mucho a la política en Chile y en numerosas democracias del mundo actual. Es una batalla que tiene posibilidades de lograr transferencias de poder más o menos espectaculares en la región de la “democracia incompleta” que es América Latina. En este sentido, los trabajos liderados por Patricia Arancibia contribuyen a enriquecer un cuadro que muchas veces, al pensar el país de nuestra época, aquel de la segunda mitad del siglo XX y de la primera década del dos mil, aparece excesivamente monocorde.

Este tipo de trabajos tiene antecedente también en el periodismo de nivel, como en los casos de Patricia Politzer, Raquel Correa, Florencia Varas y Patricia Verdugo, y algunos más que se nos pueden escapar. Claro que los libros de Patricia Arancibia poseen mayor sistematicidad y rigurosidad para recoger de manera más completa los testimonios. Al igual que ocurre con sus antecesoras del periodismo, sus libros han alcanzado a un público más amplio que aquel del mundo académico o de una clase intelectual, circuito al que muchas veces han estado condenados los historiadores profesionales. Constituyen en cierta medida también un tipo de material que está a medio camino entre lo que los historiadores llaman "fuente" (la huella de la historia) y el relato que se hace a partir de ella. Su valor es similar al de las memorias, y quizás pueden ser tan discutidos en su valor epistemológico como este último género. Siempre gira en torno a ellos la sospecha de que son "memorias selectivas”, que justifican la actuación del entrevistado o memorista como un cuento de hadas, como hagiografía; en suma, son poco creíbles.

Esto por cierto es un problema real en este tipo de literatura si no somos capaces de someter a todas las piezas del género, no sólo a las de Pinochet, sino también a las de Pablo Neruda, a esta misma clase de pruebas. Con todo, el género de memorias, como por lo demás el de biografías, seguirá constituyendo un género de literatura fascinante para cualquiera de nosotros. Mal que mal la historia del mundo es la vida de cada ser humano, y la vida de cada uno de nosotros, que es propia e insustituible, a la vez está interrelacionada por una serie de cadenas condenatorias y de maravillosos cursos de agua con todo el resto de la humanidad.

El libro de Arancibia y Balart no es una simple hagiografía, ni puede ser descartado como apología barata. Existe un esfuerzo de los autores por tratar de ver lo “peros” y los vacíos que pueden existir en el relato del entrevistado, como asimismo se intercalan numerosos testimonios de críticos de la política del ex ministro, ya sea del mismo gobierno militar como de 
algunos que tempranamente se colocaron en la oposición. No silencia las diversas críticas que necesariamente surgen ante el tema, lo que pone en alerta a un lector, v. gr., de las nuevas generaciones o sobre todo al extranjero que sólo haya escuchado lindezas acerca de Chile (baja probabilidad), de que no se está hablando de hechos aproblemáticos sino todo lo contrario. Hay dos excepciones a esto. Una es lo que se podría denominar "la relación entre la tecnocracia y la política”, un punto de referencia central en la modernidad y sobre todo para la reciente historia de Chile. La otra es el apoyo brindado a una "dictadura”, lo que permanecerá en el futuro previsible como otro tema contencioso.

La estrategia de los autores valida a pesar de ello esta especialidad de "entrevistas con la historia", título de otro libro de Patricia Arancibia que consiste en conservar testimonios mediante preguntas sistemáticas que la entrevistadora ha preparado con relativa profundidad. De esta manera, el resultado va más allá de muchas autobiografías o memorias que resultan únicamente de un "discurso" que refleja el momento en que escribe el autor. No sólo el público que la ha favorecido debe estar agradecido de este género de escribir historia. También los historiadores tienen acceso fácil a un tipo de fuente que no era nada de común en el Chile tradicional, el de antes de 1973. En ese entonces había muy poca reflexión acerca de la historia reciente del país, y casi nula escritura sobre ella. En eso ha habido un cambio monumental, aunque la lectura de la historia escrita por historiadores siga siendo marginal. Lo que no resulta marginal es aquello a lo que aludía antes, el combate por la "hegemonía cultural", por imponer un solo relato, escrito por un solo sector, que es elevado a la categoría de "historia oficial”.

No es que este tipo de historiografía (escritura de la historia) no tenga problemas, y esto se hace relevante al examinar este libro. Desde luego, no hay una exploración profunda del personaje, sus emociones, sus limitaciones, sus contradicciones. Toda vida humana es un problema, o manojo de problemas. El trabajo del biógrafo se define por la capacidad de desentrañar ese problema o problemas. Los logros del biografiado aparecerán entonces con mayor claridad y el relato será capaz de hacernos entender el calibre de la acción de éste o aquél. La historiografía testimonial, por darle un nombre a la especie a que pertenece este libro, no alcanza el nivel de rigurosidad y de crítica exigido por las reglas del juego de la disciplina.

"Crítica” en el sentido de plantear preguntas completas y de ángulos insospechados al tema, lejos eso sí de los conformismos de "ser crítico", de sentirse protagonista de un acto heroico por repetir un lugar común extraído de un catecismo político. La "crítica" del historiador se caracteriza por so- 
meter su tema a todas las preguntas que puedan levantar la tradición disciplinaria y el intelecto cultivado que debiera caracterizarlo. Para ello se debe dominar la historia de un período y las principales “cuestiones” intelectuales, las preguntas que se están planteando y que se habían planteado. Esto no sucede en el libro de nuestros autores. La historia testimonial no lo permite, aunque su presencia constituye una contribución inestimable.

\section{Especialista con personalidad pública}

Sergio de Castro Spíkula nació en Santiago el 25 de enero de 1930. El segundo de tres hermanos varones, hijo de un descendiente de español y de una descendiente de yugoeslavo e italiana. Su padre, comerciante y empresario, también ejecutivo de firmas conocidas, con práctica habitual del inglés, vivió principalmente en Bolivia durante la niñez de Sergio. Siendo adolescente, en 1946 lo envían junto con su hermano mayor a estudiar como internos en el Grange, en Santiago. Como se sabe, este colegio, sobre todo a mediados de siglo, no representaba a la clase dirigente tradicional, sino que a sectores más apegados a un ethos internacional, orientado a los países anglosajones. Después de egresar asiste a un college en Vancouver, donde se empapará más todavía del estilo riguroso de la educación en los países desarrollados, donde se extrae lo máximo de la capacidad de entrega y talento del estudiante. Estando en este lugar lo sorprende la muerte prematura de su padre y debe regresar a Chile.

Esto ya nos da material para una primera reflexión acerca de Sergio de Castro, “el arquitecto del modelo económico chileno”. Claramente en su origen no pertenece a la llamada clase alta tradicional chilena ni a ninguna oligarquía, en el sentido corriente del término. No cabe duda sin embargo de que en su origen tiene la hechura de una persona que en términos de oportunidad puede acceder a una clase dirigente, y esto lo será de sobra en su vida. Es lo que permite decir que pertenecía y no pertenecía a la clase alta chilena, aunque no tuviera una riqueza muy impresionante. Tenía las oportunidades, pero no estaba atado a convencionalismos y prejuicios del resto de la clase dirigente chilena y no se encontraba bajo el embrujo del prestigio social que, sobre todo en esa época, podía emanar de un sector tradicional, que además ya no las tenía todas consigo. Por las mismas razones tampoco era probable que desarrollara gran resentimiento hacia esos sectores, reacción nada de extraña en quienes se encuentran vinculados a medias con la clase socialmente dirigente en cualquier parte del mundo.

Tal vez esto explique también algo de las características de De Castro que lo acompañarán toda su vida pública: un cierto desenfado y algo de 
soberbia no sólo ante el conformismo y lo rutinario, sino una actitud de desapego hacia toda tradición que no fueran los ideales tradicionales (la teoría económica practicada en la universidad de Chicago) y las lealtades de grupo (su familia, lo que destaca muy claramente; su generación de compañeros de estudio). Su claridad de exposición y el blanco y negro de los horizontes a los que miraba e indicaba fueron muchas veces acompañados por un aire de insolencia hacia toda tradición y toda autoridad. Resulta sin embargo que ni toda autoridad ni toda tradición es buena o es mala de una manera tan simple.

Luego vendrá su período como estudiante universitario, en la Universidad de Chile en primer lugar, en ese entonces dominada por el lenguaje de la economía política del "desarrollo hacia adentro" que, según nos dice De Castro, le chocó por su falta de rigurosidad teórica, y después, en 1952, ingresa entonces a la Escuela de Economía de la Universidad Católica, donde será portavoz de las inquietudes de los estudiantes por modernizar la enseñanza y cambiarla desde su estilo de "escuela de negocios" a lo que sería más adelante, una de las vanguardias de los economistas que impulsarían la modernización. Todo su retrato de estos años lleno de juicios, quizás muy certeros, también rezuman un aire despectivo hacia lo que había existido hasta esos momentos. Retrata un estilo que caracterizaría después al hombre público y su desempeño como ministro; quizás sería el origen de algunos de los problemas no sólo que él tuvo, sino de los de la política económica que impulsó.

La Universidad Católica se encontraba en un proceso de enormes cambios entre las postrimerías del largo rectorado de monseñor Carlos Casanueva, quien la había consolidado, y los nuevos tiempos de monseñor Alfredo Silva Santiago, que inició una nueva puesta a punto de la cual la tan mentada reforma no fue sino la culminación. Parte de este proceso fueron los cambios en la Escuela de Economía, cuando "los viejos son barridos”, en el sentido, decimos nosotros, de que es tan característica en la vida académica la reiteración de la consigna de que hay que "barrer a los viejos”, y los jóvenes consideran después que ellos nunca llegarán a viejos. En ese entonces la generación encarnada por Sergio de Castro estuvo en la vanguardia de esta historia que se repetirá por siempre ${ }^{1}$.

Culminación de esto fue la hoy célebre firma del convenio entre la Universidad de Chicago y la Universidad Católica en 1955 para formar economistas en el rigor del desarrollo de la ciencia, tal como se estaba desarrollando en Chicago y en los grandes centros académicos norteamericanos. El nuevo decano de la facultad de economía era Julio Chaná, quien no pertene-

\footnotetext{
${ }^{1}$ Gonzalo Vial Correa, Una Trascendental Experiencia Académica, 1999.
} 
cía a este nuevo espíritu pero consideraba necesario avanzar en esa dirección. Sergio de Castro llegó a ser uno de los primeros becados de este programa que tendría una gravitación tan decisiva en el futuro.

Antes de seguir con esta historia lo que hay que hacer aquí es destacar algunos rasgos de la persona de Sergio de Castro. Ya se ha insinuado que es una persona no atada por tradiciones. Todo su saber, que llegaría a ser inmensamente respetado por muchos, se encuentra vinculado a la práctica, a la búsqueda de soluciones coherentes con su profesión. Para establecer estas salidas muestra una capacidad increíble de concentración y rigor en el análisis de los datos y antecedentes, retrotrayéndolos a su mundo conceptual y teórico y lanzándose después a su "implementación”, palabra que se puso de moda en la década de 1970 . Aunque seguro casi hasta la caricatura de la certeza de su ciencia, no muestra los rasgos de un obsesionado. Deportista, se da el tiempo para departir con amigos y familia. Hay algo de desenfado y hasta de desparpajo en él que hace que toda crítica le resbale y la pueda calificar tranquilamente como error. Razón tenía el padre de su amigo Ernesto Fontaine en que “al Tejo no le entran balas”. Quizás al propio De Castro no le molestaría que éste sea su epitafio.

Algunos hechos podrían ilustrar este tema. Los autores le recuerdan el famoso incidente cuando el general Pinochet en una reunión se refiere a que tiene "el sartén por el mango" en lo económico y De Castro espeta como desdeñosamente, "pero se va a quedar con el puro mango". Pinochet quedó furioso y De Castro no entendía por qué se había enojado. La razón económica muy anclada en el tipo psicológico de Sergio de Castro no reconoce jerarquías ni respetos. Los autores no le plantean otras situaciones parecidas, como cuando dijo burlonamente "compren dólares" a los que no creían que se podía mantener el precio de 39 pesos el dólar, pero aquéllos tuvieron la razón finalmente. Y otro célebre: "que se coman la vacas”, a los agricultores más o menos desesperados por el cambio económico, y porque la agricultura puede ser más lenta en flexibilizarse que el comercio y la industria. Fue todo un estilo de los economistas del régimen, y no sólo de los de Chicago, que parece estar perfectamente resumido en el estilo y en la acción de este Ministro de Hacienda.

Como profesor era extraordinariamente claro, riguroso y exigente, con la impaciencia de quien siente que cree haber visto el mecanismo perfecto y quiere que los demás lo conozcan también. En sus clases podía garabatear, entonces una novedad, hoy otro rasgo nihilista más. Y a la vez no cabe duda de que como economista pudo haber hecho desde joven una carrera extraordinariamente gananciosa para sus bolsillos, pero que su verdadera vocación estaba en el cultivo de la docencia y de la educación 
pública en esta ciencia que a veces parece querer ordenar la vida mucho más allá del campo económico. Y existe otra dimensión que destaca en su personalidad, al menos en lo que podemos saber de ella: que no hay dobleces en lo que pretende, que tiene un mensaje claro, que es un hombre de palabra, que es previsible. Sobre todo da la impresión de que su estrategia económica guarda relación con el núcleo principal de la economía moderna, que fue finalmente, a grandes rasgos, la más adecuada y la más promisoria en la mayoría de las sociedades del mundo. Claro, como se sabe, el demonio está en los detalles.

Una historia testimonial no permite explorar estas preguntas y muchas otras más que se podrían hacer. Tampoco existe algún asomo hacia la intimidad de De Castro, ni un intento de trazar un retrato psicológico del hombre, aunque, como decía, se entregan algunos elementos a partir de los cuales el lector se puede imaginar algo. Esto no es “anecdótico". La existencia histórica consiste en ese misterio de cómo los seres humanos se mueven con una voluntad y a la vez están siendo atraídos entre sí por fuerzas que escasamente controlan y que muchas veces llamamos "factores impersonales”, "sistemas”, “estructuras”. En la historia de este grupo liderado principalmente por De Castro están el azar y la necesidad, y no estamos seguros dónde comienza uno y dónde comienza la otra. Sencillamente es la condición humana.

\section{La crisis del "desarrollo hacia adentro"}

Todo el período que va desde 1955 hasta 1973 es seguido en este libro a través de la historia del desarrollo de las ideas del grupo que llegaría a ser conocido como "Chicago Boys". Ellos representaban la crítica a la economía política y a la estrategia de desarrollo seguida en Chile desde fines de la década de 1930, y que se la conoce indistintamente con los diversos nombres de "desarrollo hacia adentro", "industrialización vía sustitución de importaciones" (ISI), y de connotación más política, "Estado de compromiso". Se trató de un estilo de relación entre Estado y economía que por un lado deseaba crear una industria chilena protegida del exterior, al menos en un primer momento, se suponía, y por otro lado ir extendiendo beneficios sociales a una parte creciente de la población.

Era también un fenómeno latinoamericano y tenía alcances más globales, como el intervencionismo estatal, que fue una respuesta a la Gran Depresión de los años 30. En el Chile de los treinta se decía que había que tomar como modelo el “New Deal” de Roosevelt. Ante la frustración y el 
hecho de que la economía pasó a depender de una sola exportación, el cobre, crecía una poderosa crítica contra el sistema desde la izquierda marxista. En la derecha, aunque se quejaban, de hecho muchos intereses económicos estaban imbricados en este sistema. No faltaban editoriales de $\mathrm{El}$ Mercurio que veían la necesidad de una reforma. Pero el sistema político, que no carecía de virtudes (la época de la célebre "democracia chilena”), estaba paralizado sin saber reformarse a sí mismo. Éste es uno de los puntos de partida a 1973.

Cuando se firmó el convenio entre Chicago y la Universidad Católica, promovido por un programa del Departamento de Estado de los Estados Unidos, la experiencia fue contemplada como una rareza. La Facultad de Economía de la Universidad de Chile no quiso identificarse con esa parte de la academia norteamericana que era considerada demasiado ortodoxa en economía, la creían anticuada. Luis Escobar Cerda, que también sería ministro de Pinochet, estaba orientado hacia lo que se pensaba eran las políticas keynesianas, según las cuales el Estado podía controlar con fuerza muchos aspectos de la vida económica para superar las crisis y mover a la sociedad hacia un pleno empleo. La Universidad de Chicago en materias de teoría económica llegó a ser símbolo de algo que era más extendido que ella misma, que hoy día se le da el nombre de "neoliberalismo"”2, pero que pensamos es más adecuado llamarlo "revitalización de la teoría clásica”, ya que en su análisis del funcionamiento del mercado existe una clave no total y absoluta, pero sí bastante completa, de los mecanismos de la vida económica. A veces a esta nueva vida de la teoría clásica se la llama "neoclásica". Existe una confusión, ya que esta última incluye a dos almas, una es la teoría misma, como el "monetarismo", y otra es una versión que a veces llega al vértigo de un credo, de explicar la vida humana como incentivos de mercado y de “decisión (perfectamente) racional”, que linda con una religión intramundana desprovista de todo misterio. Como cualquier teoría, la económica puede ser un auxilio en esferas no económicas, pero no una doctrina para ajustar la existencia humana.

No puede existir un simple dogma de que el Estado no intervenga en la economía, sino que éste y los actores que giran en torno a él intentan ir delineando los límites que en cada época histórica tendría esta intervención. Una de las grandes paradojas del sistema chileno es que se adoptó esta estrategia como un acto voluntarioso y a veces hasta brutal por parte del Estado, como arrojándolo encima de la sociedad civil. Con las décadas esto vino a ser aceptado por las principales fuerzas del país, aunque su origen

\footnotetext{
${ }^{2}$ Sobre el problema terminológico, cfr. Enrique Ghersi, "El Mito del Neoliberalismo”, 2004.
} 
permanece como un punto frágil de la solidez del sistema. Hay que remachar que se trató de un acto de Estado, como para recordar lo que decía Mario Góngora acerca de su papel en la formación de la nacionalidad chilena ${ }^{3}$. Lo curioso es que no pocos intelectuales y académicos, entre ellos muchos de los "Chicago Boys", al menos de la boca para afuera dan la impresión de que les daría lo mismo ser o no ser chilenos, estar en éste o aquel país, siempre y cuando las cosas sean hechas de manera "correcta", en el sentido organizacional. Y no se trata de que sean cosmopolitas.

\section{De la teoría al proyecto social}

Es interesante la vida de los "Chicago" en las universidades norteamericanas a fines de lo años cincuenta. Además de Sergio de Castro estaban Víctor Ochsenius, Carlos Clavel, Carlos Massad, Luis Arturo Fuenzalida, Ernesto Fontaine. Y en Chicago tuvieron de profesores a economistas famosos, entre ellos dos futuros premios Nobel, Friedrich von Hayek y Milton Friedman, este último todo un símbolo de esta orientación, fallecido hace poco. Un importante nexo entre la Universidad Católica y la Universidad de Chicago sería el profesor Arnold Harberger, “Alito” para los que lo conocen, quien llegaría a casarse con chilena y a estar muy ligado a las relaciones chileno-norteamericanas. Harberger escribió en 1956 un extenso informe — que sólo se publicó pocos años atrás ${ }^{4}$ - sobre la economía chilena, señalando todas las críticas a ésta, pero también, lo que llama la atención, mostrando algunas de sus fortalezas y complejidades. Aunque el estilo docente de Chicago ha llegado a hacerse carne en algunas universidades en Chile, sería interesante que los estudiantes chilenos leyeran estas páginas del libro de Patricia Arancibia, y no sólo los de economía. Se muestra el estilo de enseñanza riguroso y exigente de las universidades norteamericanas, y cómo el alumno está obligado a razonar y a sacar conclusiones propias, todo ello en un ambiente en donde debe entregar casi la totalidad de sí mismo, y donde los momentos de ocio no son más que interludios de la actividad central a la cual se arrojan en un período de la vida.

Regresa de Estados Unidos en 1958 después de obtener un master (luego volverá a ese país para realizar un doctorado). En la docencia universitaria De Castro y los ahora “Chicago Boys” comenzarían a crear una gene-

${ }^{3}$ Mario Góngora, Ensayo Histórico sobre la Noción de Estado en Chile en los Siglos XIX y XX (1981), 2006.

${ }^{4}$ Arnold Harberger, "Memorandum sobre la Economía Chilena", publicado recién el año 2000 en Estudios Públicos. 
ración marcada por esa escuela y tendrían una enorme influencia incluso antes de 1973. Su influencia no se limitaría a la formación profesional de los estudiantes de economía en Chile sino que tendría contrapartes en otros países de América Latina. También serían parte de una polémica que iría creciendo en Chile acerca de la estrategia para escapar del cuello de botella económico y político que estaba lentamente paralizando la democracia chilena.

Articulistas del diario El Mercurio se enfrentaban a los partidarios de un desarrollo dirigido. Estos últimos escribían desde Panorama Económico, publicación que acogía a los economistas de la Universidad de Chile, entre ellos Aníbal Pinto Santa Cruz. En la década de 1960 Sergio de Castro se integra no sólo a estos debates públicos sino que con la creación del Centro de Estudios Socioeconómicos (CESEC), financiado por las empresas del grupo Edwards — cuyo representante más destacado era Carlos Urenda—, comenzaría a reunir a cabezas pensantes en lo económico y en lo político para desarrollar políticas públicas que tendieran a darles mayor poder al mercado y a la apertura internacional en el desarrollo de la economía chilena. La Sociedad de Fomento Fabril organizó cursos de estos economistas para ponerlos en contacto con empresarios. A los nombres antes dichos habría que agregar los de otros economistas, como Pablo Barahona, Manuel Cruzat y Rolf Lüders. Paralelamente, desde fines de la década de $1960 \mathrm{El}$ Mercurio desarrolló en la "Página Económica"5 una pedagogía en economía política recurriendo a las plumas de estos economistas, depuradas a mejor castellano por Arturo Fontaine.

Pero no todos los economistas provenían exclusivamente de la Universidad Católica; iría creciendo también una formación "transversal”, como se dice ahora. A esto hay que agregar un grupo de empresarios con una mentalidad más general, que iban más allá de la defensa de intereses particulares. Además de Agustín Edwards estaban, por cierto, Ramón Samaniego, Ernesto Ayala, Eugenio Heiremans, Francisco Soza, Jorge Ross, Fernando Léniz, Jorge Yarur. No siempre todos ellos concordaban con la visión de estos economistas, muchos de ellos estaban vinculados al círculo de Jorge Alessandri, quien quería reformas sustanciales pero desconfiaba de visiones que consideraba muy teóricas, precisamente como la representada por Sergio de Castro. Esto refuerza la impresión de que hubo una voluntad en la esfera de "economía política", de la sociedad civil, por reformar la economía y la sociedad en un sentido diferente del que predominaba desde 1938.

5 Ángel Soto, El Mercurio y la Difusión del Pensamiento Político-Económico Liberal 1955-1970, 2003. 
Si mientras en Chile se incrementaban el discurso y el sentimiento favorable a un Estado empresario, propietario, y a las bondades del "socialismo" en sus diversas tonalidades, De Castro era parte de un sentimiento minoritario en términos de números, pero de creciente importancia en cuanto a formar una mentalidad de economía política que diera respuesta al estancamiento del país. Esto tiene raíces en las críticas a la Corfo en las décadas del 40 y del 50 y en el cuasi descalabro provocado por las políticas desarrolladas a medias tras el informe de la Misión Klein-Saks en 1956. Las ideas desarrolladas ante el público por Jorge Alessandri y Eduardo Frei Montalva al final de sus respectivas administraciones no diferían tanto entre sí. Cuando se analiza los años de Frei Montalva se pasa por alto este desarrollo y sólo se ve cómo una parte de la Democracia Cristiana fue ganada por la divisa de indudable corazón marxista, la "vía no capitalista de desarrollo". Pero en las palabras del propio Frei y de algunos de sus personeros surgía la convicción de que la capacidad del Estado tenía sus límites. Frei mismo señaló repetidas veces que la vía tributaria estaba agotada. Intentó poner en marcha una reforma con Raúl Sáez en Hacienda. Duró un mes. (Hay que preguntarse, como hipótesis contrafactual, si no hubiese sucedido lo mismo con Sergio De Castro nombrado con gran respaldo pero en un sistema democrático "normal”.)

Los economistas en torno a De Castro a veces eran consultados por el gobierno. Por lo demás Álvaro Bardón y Jorge Cauas eran o pasaban por democratacristianos. Algunos de estos economistas votaron por Tomic, y otros hasta fueron consultados esporádicamente por el Banco Central en los años de la Unidad Popular. Sergio de Castro, sin caracterizarse por tener ideas específicamente políticas, gira en torno a grupos y sentimientos que deseaban insuflarle nueva vida a la derecha.

Esto incluyó la crisis en la Universidad Católica de Chile, desatada por la "toma" del 11 de agosto de 1967, que representaba la eclosión del "espíritu de los sesenta” y que rápidamente sería semillero de nuevas orientaciones políticas, el Mapu y, sobre todo, Jaime Guzmán y los suyos. La Facultad de Economía, con asiento en el barrio Los Dominicos, fue la única en no ser tomada, defendida por profesores y alumnos de todas las tendencias, lo que mostraba que había adquirido esprit de corps. Como decano de la facultad y miembro del Consejo Superior, De Castro se perfiló como opuesto a la politización, compañera inseparable de aquella reforma. Encabezó una oposición visible por el papel desempeñado por el cardenal Raúl Silva Henríquez en ese conflicto. Le envió una carta que entre otras cosas le decía "(por) todo lo dicho estimo que la palabra interventor describiría mejor que mediador las funciones que usted ha asumido” (p. 121). La marea refor- 
mista arrasó con todo y Sergio de Castro votó por Ricardo Krebs como próximo rector, pero poco se podía hacer ante Fernando Castillo Velasco, candidato que a todas luces sería elegido.

\section{De Jorge Alessandri a la Unidad Popular}

Lo que es revelador en De Castro, en los años que seguirían hasta 1973, es su participación en organizar el programa de gobierno de la candidatura de Jorge Alessandri para las elecciones presidenciales de 1970. En este episodio Sergio de Castro jugaría un rol clave. Los economistas representados por De Castro y agrupados en torno al CESEC eran partidarios de enfocar la campaña como una clara confrontación entre dos concepciones, una libertaria y otra marxista. Se pensaba que ante una ideología tan definida en tantos aspectos como la marxista había que poner un orden de libertad igualmente destacable.

Pero aquí comienzan las dificultades de muchas persuasiones políticas que querían oponerse al marxismo pero envidiaban en éste su omnisciencia, su respuesta única para toda la compleja variedad de la vida. La Democracia Cristiana había caído en esta trampa en los sesenta, los liberales económicos como De Castro intentaron aplicar su propia respuesta única durante el gobierno militar, con algunos éxitos y con las limitaciones que luego se señalarán. La fortaleza del “modelo occidental”, esto es la democracia moderna, no radica en dar respuestas totales, sino en demostrar la falacia de las presuntas respuestas totales. Y la parte política de la campaña de don Jorge se daba cuenta de que el lenguaje económico no iba a ser comprendido por una gran masa del electorado que veía en su candidatura más bien una fuente de estabilidad en época de incertidumbre.

Dentro de esta candidatura hubo también diferencias sobre un tema que provocó más roces. Los economistas del tipo de De Castro consideraban que para imponer en Chile una estrategia de desarrollo que realmente tuviera algún sentido había que llevar a cabo un cambio drástico en la estrategia económica. Todo el sector político de la campaña de Alessandri quería reformas, pero se dudaba de la prudencia de proponer un cambio muy radical que pudiera ser resistido por una población acostumbrada a las huelgas y por un movimiento sindical reivindicacionista muy poderoso, que además lograba defender ciertas parcelas a cualquier costo.

$\mathrm{Y}$ segundo, De Castro y los suyos eran muy taxativos en darle un papel protagónico al mercado, mientras la derecha política y el mismo Jorge Alessandri querían manejar más eficientemente el Estado pero no reformarlo 
drásticamente, y el mismo Jorge Alessandri creía, y seguiría creyendo después, que el Estado tenía un papel central en la economía. Como se formaron dos bandos en la candidatura, esto fue dirimido en una reunión a la que asistió el propio Jorge Alessandri. En esa reunión hubo como un anticipo de la frase del sartén y el mango, en cuanto De Castro emitió un gesto de desenfado por la "tontería" que se estaba planteando por parte del sector político, y Alessandri reaccionó airado. De Castro repitió todas las razones, sin duda muy poderosas, para apoyar una política que en el futuro sería llamada de "shock". Al final Jorge Alessandri, viejo zorro político, dice que las diferencias son semánticas y que se irían arreglando en el camino. No quería crear conflicto en medio de una campaña ajustada y que además se veía afectada por una pésima publicidad. Pero las relaciones entre Sergio de Castro y Jorge Alessandri permanecerían bastantes complicadas en el futuro y desempeñarían un papel tanto en su salida del gabinete como en la devaluación del peso en 1982, lo que está narrado con cierto detalle en el libro.

Hay que detenerse en esto que no pertenece al gran momento de la actuación de De Castro, pero que es revelador del fondo del problema, la relación entre dos órdenes que son diferentes pero que en la realidad concreta deben estar unidos: la "razón económica", que sabe que existe una lógica mínima inexorable dentro de la cual los seres humanos producen, intercambian, ahorran e invierten, y el "criterio político"6. Y no existe receta infalible para saltar de la una al otro.

Una expresión de De Castro nos ilumina algo acerca de esto, que es reveladora quizás de todo el problema que arroja este libro. Dice De Castro, "[Si] Salvador Allende me hubiera llamado para que le hiciera un programa yo se lo hubiera redactado sin ningún inconveniente, pero siempre que ése y ningún otro fuera el programa a aplicar de verdad” (página 133). ¿Estamos aquí ante la "razón tecnocrática"? Aun teniendo en cuenta que aquí De Castro está respondiendo a una pregunta que le hace uno de los autores del libro, y que por tanto no refleja obligatoriamente la mentalidad de De Castro en los años setenta, uno sospecha que es completamente paradigmática de la visión de quien por profesión y talante cree en la organización social, en el funcionamiento de un sistema, en la superioridad casi ética de la lógica inexorable del hombre económico. La política estaría para simplemente ejecutar ese orden al que sólo los necios pueden ponerle alguna objeción. Para poner las cosas en su contexto no hay que olvidar que Chile había estado por muchas décadas acostumbrado a un lenguaje que creía que el orden

6 “Criterio político" en el sentido que lo ha explicado Isaiah Berlin en su ensayo "Political Judgement". 
político crearía una realidad económica, lo que a su manera reflejaba una tecnocracia travestida. También, como se ha dicho, la crítica reflejada por gente como Sergio de Castro había comenzado antes y advertía que las reformas económicas necesarias iban a tener un costo crecientemente mayor.

Pero no existe en De Castro, y en este tipo humano, ni una huella de rechazo al marxismo como sistema, salvo porque "llevaba a cabo una deficiente asignación de recursos”. Para ser justos, hay que decir que antes de la crisis de los sistemas marxistas no faltaban los economistas occidentales y más que nada muchísimos empresarios occidentales que admiraban la planificación y el output soviético o chino, aunque este último haya sido en esta época más que risible. En los años de la Unidad Popular De Castro fue de esos privilegiados que habría encontrado un puesto promisorio en muchas partes del mundo, pero que prefirió permanecer en Chile. Quizás un instinto de “gallo de pelea” lo hizo permanecer en el país en el cual ya antes del 11 de septiembre de 1973 empezaría a ocupar un puesto protagónico entre quienes comenzaban a diseñar un plan de gobierno para un régimen post Unidad Popular. Se siguieron refinando las ideas que habían estado en la base de la campaña de Alessandri y de ahí surgiría un plan más o menos completo de reforma económica que empezó a circular entre algunos economistas y muy luego, quizás por vía de Hernán Cubillos, llegó a las manos del alto mando de la Armada, que ya sentía la presión pero quería tener alguna especie de programa. Este proyecto es lo que se llegaría a conocer con el nombre de "el ladrillo” y que recién en los años noventa sería publicado y por ende accesible a un gran público ${ }^{7}$.

Las ideas contenidas en El Ladrillo son, si se quiere, simples, sólo que están escritas con buena lógica y tras de ellas hay especialistas formados en los mejores lugares del mundo, aunque esto no es garantía de sabiduría en la ejecución de las políticas. Básicamente están en la línea de que el problema central de Chile en lo económico se caracterizaba por una economía orientada a producir bienes para el mercado interno, deficientes y caros, por lo que había que orientar la producción hacia el mercado internacional, combatir la inflación atacando los problemas monetarios, abrir la economía, lo que promovería la competencia y abarataría los productos, dar garantías de propiedad tanto a los empresarios chilenos como al capital internacional e integrarse a la dinámica de la economía mundial. Era terminar con el "desarrollo hacia adentro” — característico desde los años de la Corfo_-, aunque a la vez era terminar con gran parte del Estado empresario y con las diversas

${ }^{7}$ El Ladrillo, 1992. 
versiones de lo que se ha llamado socialismo, aunque no era imposible que conviviera con una llamada socialdemocracia, tal como ésta se había desarrollado en Europa en el siglo veinte. Hasta la década de 1990 éste era un programa muy difícil, por no decir imposible, de llevar a cabo en un país latinoamericano que funcionara democráticamente (eran muy pocos los que lo hacían). Aquí está la raíz del "pecado original” del modelo chileno ${ }^{8}$.

\section{El arquitecto lleva sus planos a la práctica}

Naturalmente que el nombre de Sergio de Castro está ligado a la puesta en marcha del programa económico del gobierno militar y a la modernización económica del país que creó aquello del "modelo chileno". La historia que se relata en este libro no es del todo nueva y muchas de sus cuestiones principales ya habían sido desarrolladas. Pero los aportes que hacen los autores, aunque circunscritos a algunos elementos, son sin embargo fundamentales. Primero, destacar el papel central que tuvo el Ministro del Hacienda. Aunque cuando se estudia a un actor individual siempre existe el riesgo de sobrevaluar su efecto en el desarrollo de los acontecimientos, poca duda cabe de que Sergio de Castro es el representante más acusado de ese verdadero equipo que se le conoce genéricamente como "Chicago Boys". Nada menos que el presidente Ricardo Lagos dijo una vez en el Centro de Estudios Públicos que Sergio de Castro había sido "el Ministro de Hacienda más influyente desde Rengifo", el ministro de los años de Portales.

Aquí hay una historia detallada, a veces día a día y hora a hora, de los acontecimientos. En segundo lugar este libro contribuye a completar la idea de que el programa político del gobierno militar no sólo fue impuesto manu militari, porque simplemente no había cabida para la existencia de una oposición pública abierta de gremios y sindicatos y de actores políticos, sino impuesto también a pesar de la oposición, a veces muy beligerante, de sectores uniformados, destacando el general Gustavo Leigh, pero no sólo él. De hecho la única vez que se nombra en este libro a los autores de la DINA es por la oposición de ésta al programa económico encarnado por De Castro. Curiosamente esto no habla tan mal de la DINA porque su preocupación era el costo social que significaba. De la otra política llevada a cabo por la DINA no hay mayor mención en el libro.

${ }^{8}$ Se ha publicado una ya ingente bibliografía sobre este tema, que es recogida en este libro. Como obras de investigaciones e interpretaciones diferentes, se puede nombrar la de Arturo Fontaine Aldunate, Los Economistas y el Presidente Pinochet, de 1988, y la de Juan Gabriel Valdés, La Escuela de Chicago, de 1989. 
Esta oposición también incluía a destacados economistas como Raúl Sáez, que durante el primer año del gobierno militar fue un hombre de absoluta confianza de la Junta, e incluso a sectores empresariales. Además, como se ve tan expresamente en el libro, la oposición política al régimen militar pudo expresarse en general no por críticas abiertamente políticas (“elecciones libre”, “no a la represión”), sino que como crítica a la política económica. La revista Mensaje, la revista Ercilla hasta 1975, y a partir de ahí la revista Hoy serían la punta de lanza de esta oposición que era también una oposición política. Las homilías del cardenal Raúl Silva Henríquez se detenían principalmente en este punto.

El libro ofrece también más elementos de juicio para comprender a Pinochet como jefe político y como administrador del Estado. Las relaciones de De Castro con Pinochet ocupan un lugar esencial en la argumentación testimonial del ex ministro a lo largo del libro. Si bien Pinochet fue el factor decisivo para facilitar el desarrollo de la estrategia económica, no es que no tuviera ninguna desconfianza de ella y sus ejecutores. En esto se entrecruza el gestor del Estado con el jefe político peculiar que era Pinochet. De Castro entrega un perfil de su personalidad tal como la veía él, sin dejar de recordar que lo estaba diciendo treinta años después:

El Presidente era un hombre que se imponía por presencia. Afectuoso en el trato, a veces me permitía algunas licencias con él, pues tenía sentido del humor y habíamos logrado cierta afinidad especial. Carecía de complejos y se entendía con naturalidad con todo tipo de personas, independiente de su condición social o intelectual. Valeroso en lo moral y en lo físico, irradiaba seguridad en sí mismo. Escuchaba atentamente y comprendía con rapidez el núcleo de los problemas, sacando por su cuenta las derivadas del caso. Muchas veces me pasaba papelitos con ciertos temas que le preocupaban para que le ayudara a buscar soluciones, y otras tantas cuando yo le ponía la proa, me decía: "Sergio, usted no las puede ganar todas". Además, siempre trabajó de a sol a sombra y a luna, como enano, y eso se notaba. En cualquier asunto que se discutiera él estaba preparado, había leído los antecedentes, tenía minutas a mano, se había informado preguntando a mucha gente, había trabajado el asunto. (P. 251y s.)

Este retrato del general Pinochet seguramente será rechazado por muchos, y desde luego se puede decir con tranquilidad que al menos es incompleto. Sin embargo es coherente con el que han hecho muchos de los que lo trataron, e incluso con el de algunos que se le oponían y que de una 
manera u otra pudieron sostener grandes conversaciones con él. Es un Pinochet trabajador, eficiente, disciplinado hasta lo increíble, astuto, socarón, bonachón con sus amigos y con sus ayudantes, aunque rápidamente eso se puede transformar en grito seco y bastante brutal y vulgar para quien no entienda la cultura militar. Algunas de estas características están por lo demás presentes en los jefes de cualquier sistema de mando, en cualquier organización.

El mismo ex ministro dice que cuando Pinochet estaba de mala o tenía que llamar la atención lo llamaba "De Castro", o espetaba "que venga De Castro”, pero había escalas más cordiales y afectuosas que iban desde “Ministro” a afectuosamente "Sergio”. En otro episodio revelador Pinochet una vez le ordena expulsar del equipo a Ernesto Silva, por haberse pronunciado a favor de la privatización de Codelco. De Castro apeló ante el mismo Pinochet indicándole que Silva era una persona fundamental para el equipo. No hubo caso. De Castro quedó cavilando hasta que descubrió la madre del cordero: que Pinochet le estaba dando una advertencia a él mismo de que no se pida la privatización de Codelco, que lo dejara tranquilo porque eso despertaba mucha oposición en las Fuerzas Armadas, y que el que mandaba no era el ministro, sino que Pinochet en persona, que no se olvidara. Esta idea se vio reforzada después porque el mismo Pinochet mantuvo buenas relaciones con Ernesto Silva. El coscacho había sido para De Castro.

La descripción de De Castro tiene credibilidad además por razones que podríamos llamar de "sistema”. La dictadura de Pinochet pertenecía a una tipología. Claramente no era el dictador totalitario, como tampoco era un simple déspota en un Estado cuasi patrimonial (aunque dentro de la tradición chilena algo se acercó a este tipo). Pertenece más bien al tipo de “dictadura de desarrollo” que emergía de la guerra civil política que caracterizó a Chile entre 1972 y 1973, y que en los tres años que siguieron al 11 de septiembre de 1973 desata una guerra interna con caracteres sanguinarios contra algunos de sus enemigos. El "régimen de Pinochet” era semiinstitucional y semipersonal, esto es, no era completamente ni lo uno ni lo otro. A pesar de que Pinochet se elevó a sí mismo como una suerte de líder máximo chileno, este libro demuestra palmariamente cómo Pinochet tenía que consultar constantemente la opinión de los miembros de la Junta y que cada una de las ramas uniformadas mantuvieron algún peso en decisiones generales del Estado. No era el dictador caribeño retratado por Mario Varga Llosa en La Fiesta del Chivo. A pesar de que en algunos sentidos la de Trujillo también fue una dictadura de desarrollo. Y también Pinochet dependía del apoyo de fuerzas chilenas, en buen romance, sectores políticos afi- 
nes que tenían capacidad de acción pública, de los cuales los gremiales de Jaime Guzmán son uno de varios ejemplos.

Esto hace muy creíble que el gobierno y el mismo Pinochet estuvieran dominados por un mismo ethos de eficiencia en el proyecto de transformar al Estado y transformar la economía, y después en el proyecto de crear un nuevo sistema político con una democracia limitada, supervigilada por las fuerzas armadas, por el "espíritu Pinochet”, se supone. De Castro relata cómo a partir de 1978, con la llegada del ministerio encabezado por Sergio Fernández, había constantes reuniones para tratar temas políticos sobre el futuro desarrollo institucional. A partir del relato que él entrega da la impresión de que esto no era un gran tema hasta ese momento. Lo que no quita que Pinochet se haya hecho sentir como el jefe todopoderoso, de lo cual hay muchos testimonios en la acción del gobierno a lo largo de los diecisiete años, aunque hay una transformación política entre querida y no querida por el régimen militar, transformación cuyo eje está probablemente en el año 1980.

\section{La estrategia}

De Castro va a ocupar varios puestos clave desde septiembre del 73 y junto con Jorge Cauas no cabe duda de que fueron las personas más claves de todo el grupo denominado “Chicago Boys”, aunque Cauas y varios otros de los que aparecen en el libro, como Hernán Büchi, no se doctoraron precisamente en Chicago, si bien representaban un mismo proyecto acerca del orden económico. Hoy día aparece como un sencillo orden lógico el que estos economistas hayan desarrollado un conjunto de políticas que por lo demás fueron plenamente asumidas por los economistas de la Concertación. Sin embargo hay dos aspectos que se deben analizar en torno a su influencia.

En primer lugar está lo que aparece con un aspecto azaroso, el cómo llegaron a ocupar un papel rector en la economía de los años setenta y después. Esto ha dado pábulo a la idea de la “conspiración”, de que hubo una planificación secreta mezcla chilena mezcla norteamericana, primero para terminar con la experiencia socialista y segundo para volver a permitir una acumulación propia del “capitalismo salvaje”. Y que después este proyecto se insertaba dentro de una estrategia de globalización dirigida por el “capitalismo”. El estudio detallado del período no permite sostener esta descripción. La oposición de sectores empresariales, la oposición sobre todo de muchos sectores de las fuerzas armadas, incluyendo al Ejército, la 
oposición de muchos gremios y sindicatos fuertes que en los primeros años además apoyaban al gobierno militar, hace ver que este grupo se impuso por algo más que sus credenciales académicas. La importancia de El Mercurio, de la Armada (a veces) y de algunos sectores económicos no alcanzaría a explicar el protagonismo de los "Chicago Boys" en la reformulación del Estado. Lo que cierra el círculo es el apoyo casi irrestricto que les dio el general Pinochet.

¿Por qué tomó esta decisión? Se ha hablado mucho, y el libro es un testimonio más acerca de cómo las fuerzas armadas estaban muy identificadas con el sistema ISI, es decir, con la economía política que va de los treinta a los setenta. El mismo Pinochet entendía poco y nada del asunto, pero esto no es lo clave en un mando político, ya que el mismo Ronald Reagan entendía mucho menos que Pinochet en términos comparativos ${ }^{9}$. Éste pensaba en términos de asentar su propio poder dentro de la Junta y dentro del Estado y de asociar su nombre a un gran proyecto de renovación. La vía marxista había sido contra lo que se habían rebelado los militares.

Los economistas que muy temprano comenzaron a criticar públicamente la política económica del gobierno estaban ligados a una causa política en torno a Eduardo Frei, por dar un nombre, que demandaba una rápida entrega del poder a un gobierno electo o que condujera a una elección. Por cierto, esto no era alternativa para Pinochet y ni siquiera para los oficiales que habían organizado el 11 de septiembre. También esos economistas anunciaron, en forma unánime, que las medidas de los "Chicago Boys" no podían resultar. A su vez había otros economistas que pensaban que se podría recurrir a otras formas de contemporizar, deshacer algunos de los entuertos de la Unidad Popular, devolver algunas de las expropiaciones, dar garantías al capital nacional e internacional y regresar en lo básico a 1970.

Quizás Raúl Sáez, que tanta importancia tuvo en los años de la Corfo y durante el primer año del gobierno militar, hubiera podido recomendar eso último, pero, de acuerdo a éste y a otros testimonios, Sáez no supo o no quiso proponer una estrategia más o menos coherente, como tampoco reaccionó a la urgencia del momento, esto es, a la falta de reservas y de capital para inversiones que había legado la Unidad Popular. A su vez, el aislamiento político internacional hacía ver que en el futuro se tendría que renegociar la deuda externa, aparte de las que gestionó Raúl Sáez en 1974 y 1975. Todo esto, además, exacerbado por la recesión internacional que incluía la caída

${ }^{9}$ Aunque en el caso de Reagan su firme convicción política había estado precedida por más de treinta años de una suerte de ideología del liberalismo ("conservadurismo” en el mundo político norteamericano) económico. 
del cobre y el alza del petróleo. Fueron los años del "shock petrolero” y de una situación catastrófica en términos financieros. Esta realidad amenazaba la existencia misma del gobierno militar. La ocasión demandaba medidas extraordinarias.

Es aquí donde entran los “Chicago Boys” y Pinochet. Para su mentalidad militar y para su ambicioso proyecto encajaban como anillo al dedo. No eran una o dos personas, representaban un equipo y un plan con alto grado de lógica interna (que no es la verdad por antonomasia). Un plan siempre es de gusto del mundo militar. También Pinochet, que tenía el don de captar el carácter de una personalidad con un golpe de vista, leyó claramente en ellos una gran ambición profesional y un amor por sus ideas, pero prácticamente ninguna ambición política en el sentido tradicional del término. Aparte de ello, algunos eran bastante jóvenes, y si tenían ambiciones políticas, tenían tiempo para desarrollarlas en el futuro. Miradas así las cosas eran como el ideal de una tecnocracia.

El libro en lo sustancial termina con la salida de De Castro del gabinete en 1982 y con la devaluación posterior, no aparece nada de si hubo desilusión de Pinochet con este grupo de tecnócratas. Como en todas las cortes, la intriga y la maledicencia contra los “Chicago Boys” envolvía el entorno de Pinochet, e indudablemente esto tuvo su efecto a raíz de la pavorosa crisis de 1982. Sin embargo ni aun en el período que tiene a Luis Escobar Cerda en Hacienda y a Sergio Onofre Jarpa en Interior, críticos de los “Chicago Boys”, dejó de contar con algunos de sus seguidores ni se apartó mucho de su estrategia. Después, con Hernán Büchi se vuelve a ella para desarrollar entre 1985-1989 otra etapa creativa y muy exitosa, eso sí porque antes ya se había pagado gran parte del precio.

\section{La lógica de la idea y la realidad}

El relato de estos años añade mucho a lo que sería fácil de suponer, la tarea casi titánica de ir ordenando una economía desquiciada y careciendo de todo tipo de recursos; de convencer a la parte política del gobierno de la viabilidad del proyecto diseñado en El Ladrillo, adornado como "economía social de mercado": aunque representaban un grupo con ideas homogéneas, ello no implicaba la misma facilidad de armar equipos, como lo demostró su relación con José Piñera, un llanero solitario en el gobierno militar, aunque creador de algunas políticas claves (De Castro le baja el perfil a su participación). 
Desde el punto de vista de un estudioso y observador de la época, faltan varios temas, más allá de que siempre un libro, y sobre todo si es bueno, despierta nuestra curiosidad por preguntas que no podemos respondernos, y que a lo mejor no podía responder. Para empezar, de toda nueva política económica introducida por los gobiernos a partir de la Misión Kemmerer en adelante, se esperaba que tuviera resultados palpables en un plazo relativamente breve. Esto era un problema mayúsculo, ya que en términos reales una mejoría verdadera sólo podía arribar después de un tiempo, generalmente cuando el gobierno respectivo ya se había desgastado.

Esto llegó a un paroxismo durante la época de la Unidad Popular cuando se intentó una redistribución mediante el viejo sueño del pibe de fabricar billetes. Mostró un éxito político inmediato y eficaz, que se vio reflejado en las elecciones municipales de abril de 1971, en que la Unidad Popular obtuvo estrechamente una mayoría absoluta. La perdería poco después por la polarización y porque el recurso a lo Condorito de la fábrica de monedas se desplomó en el segundo semestre de 1971. Existe en la experiencia de la Unidad Popular una gran analogía con el caso de Hugo Chávez en Venezuela, de un resultado a la inversa. Desde un comienzo Chávez ha tenido una mayoría amplia detrás de sí y sus recursos, en vez de agotarse, parecen aumentar incesantemente. Nada se saca con señalar que a largo plazo a Venezuela no le puede ir bien, porque el caudillo ha obtenido hasta ahora el triunfo político que buscaba.

Después del 11 de septiembre era imposible obtener ventajas en un corto plazo. La carencia de recursos dentro del país y la crisis internacional agravarían terriblemente la situación. Más todavía, aunque esto no se desprende del libro de los autores, una historia interna de la batalla por la supervivencia económica podría demostrar cómo entre 1973 y comienzos de 1977 no estaba nada de claro cómo iban a terminar las cosas. Cuando se tapaba un hoyo aparecía otro, y muchas medidas no entregaban el resultado previsto; muchas promesas expresadas por Pinochet y la Junta tenían que recogerse al poco tiempo. Si recordamos la experiencia con los VHR/ BHR en 1975, vemos que se parece mucho al "corralito" argentino del año 2001, una expropiación temporal de los ahorros de la población. Como señalamos antes, era un panorama que parecía hundirse y hundirse, la supervivencia de este proyecto tuvo que ver más bien con que nadie que girara en torno a la Junta tenía un verdadero proyecto alternativo, salvo aquellos economistas democratacristianos que inicialmente trabajaron con la Junta, pero que ofrecían el camino del llamado a elecciones que en la práctica sólo podía significar la entrega del gobierno a Eduardo Frei y los suyos. La 
respuesta de (todos) los militares era "no hicimos el trabajo sucio para que otros hicieran el trabajo limpio".

La lógica de imponer un proyecto estaba acompañada de una conciencia de poseer la herramienta infalible, de disponer una verdad absoluta $\mathrm{y}$, en lo que aparece incluso en la larga entrevista que es la columna vertebral de este libro, de que todos los sacrificios económicos eran completamente inevitables y necesarios. Lo que sucedió en los años que siguieron al 11 de septiembre de 1973 constituyó no sólo una reorganización económica y financiera del país como consecuencia de la caída al precipicio de los años anteriores. También fue una transición querida, impuesta, organizada y llevada adelante “cueste lo que cueste”, desde la economía política de los años de la Corfo o ISI hasta una economía de mercado inspirada en las estrategias neoclásicas cuya vanguardia había sido el espíritu de Chicago.

Ésta no ha sido una experiencia única en la historia del siglo XX ni en la actualidad. En cierto grado fue la experiencia alemana de la postguerra; con un pequeño matiz lo fueron también la experiencia inglesa de Margaret Thatcher y la norteamericana de Ronald Reagan; la Europa de después del shock petrolero se ha ido adaptando, y los debates políticos de Francia y Alemania tienen algo que ver con este fenómeno. Por supuesto, es además la experiencia de los ex países comunistas en Europa, así como de China y de Vietnam, que son casos especiales, y de la India en el momento en que se escriben estas líneas. Existe un material comparable, aunque, desde luego, hay que tener extremo cuidado de no hacer generalizaciones apresuradas. En todos estos casos ha habido buenas y malas experiencias, ha habido ganadores y perdedores dentro de cada una de estas sociedades y entre los diferentes países. Se habla del exitoso caso chino, pero no es que muchos chinos no hayan sufrido en esta experiencia. Y en Rusia, por más que uno pueda estar feliz con el desplome del comunismo, no cabe duda que la transición económica fue catastrófica por muchas razones, no en último término porque la clase dirigente comunista se autoprivatizó, es decir, se quedó con los medios de producción. ¿Cómo se compara Chile con estos ejemplos?

\section{9. ¿Pudo exigirse menos sacrificio económico?}

Desde luego el Chile de 1973 no era una economía socialista o marxista en el sentido riguroso del término. La economía tenía muchos elementos de mercado, aunque estaban conmocionados por el terremoto político que habían experimentado. El caso chileno es más comparable con el de la Inglaterra de Margaret Thatcher, aunque, por favor, no se crea aquello de 
que somos "los ingleses de Sudamérica”. Para empezar, los sacrificios fueron mucho más altos, aunque si sumamos los casi diecisiete años del régimen militar podemos considerar la estrategia como claramente exitosa. Primero, y aquí sumaremos toda la historia del período, en 1973 bajó el producto en un 5\% (en parte debido a la crisis política), pero en 1975 y en 1982 el producto bajó casi un 14\% cada vez. En 2002, el año de la crisis por excelencia de Argentina, la baja del producto llegó casi a un 12\%. En Chile sólo la caída entre 1929 y 1932, de un 50\% del producto, constituye un telón de fondo que opaca estas otras crisis. En suma, lo que nos indican estas cifras es un estancamiento primero y luego la herencia de una crisis, pero es probable también que nos indiquen que el sacrificio que sobrellevó la población pudo ser menor.

Los chilenos tienden a acordarse de la crisis de 1982, para muchos la "crisis de la banca”, aunque eso es una parte del panorama. Y si se habla de mediados de los setenta se piensa inmediatamente en la represión política, aunque es probable que una inmensa mayoría de la población no haya tomado mucha nota de ello. Si volvemos a ese momento por medio de una máquina del tiempo, lo que más se notaría es la angustia económica de la población, con un desempleo creciendo constantemente a fines de 1973 y que se dispara en 1975 hasta alcanzar a una cuarta parte de la población activa, y hasta ese mismo año al menos la inflación continuaba siendo más alta que la de 1972. Incluso hubo una rabia sorda en gran parte de la población que había apoyado con entusiasmo el 11 de septiembre y que ahora se sentía engañada, utilizada, olvidada. Seguramente una mayoría de la población en general consideraba que su situación había empeorado drásticamente en comparación con los años de la Unidad Popular. Hubo un empobrecimiento general de la población que era visible para quien tuviera ojos y oídos.

Desde luego no se deben olvidar tres factores centrales. El agotamiento del sistema Corfo en la década de 1950 y 1960, la crisis producida por la política de la Unidad Popular y el efecto imprevisible del "shock petrolero”. Sin embargo, la gran caída del año 75 y la que después se repetirá por causas algo diferentes en 1982 y 1983 es imposible pensarlas sin considerar ciertas carencias de la conducción económica del país. Es probable que hayan fallado ciertos criterios de economía política en la dirección del Estado, porque este escenario de ninguna manera es comparable con el de la Inglaterra de Margaret Thatcher, donde también hubo un alto desempleo en los primeros años. Si de tipología se trata, el modelo chileno algo se aproxima al modelo ruso de la década de 1990. 
Es probable que la respuesta esté en una crítica que se les hacía a los "Chicago Boys", a saber, la de traducir la teoría, en forma directa y sin sabiduría práctica, a la realidad de una cierta hybris propia de la tecnocracia. Y aquí está también, a lo que volveremos poco después, el hecho de que en este momento crítico de 1975 tenían el apoyo de un aparato represor nunca visto en la historia de Chile. Hay que reconocer que para la crisis de 1982 eran otras las condiciones políticas y sin embargo hubo una recuperación de la estrategia central del gobierno militar. Para hacer una comparación con otras dos acciones de economía práctica y aun teniendo en cuenta las grandes diferencias de tiempo y lugar, las gestiones de Gustavo Ross en los treinta y de Hernán Büchi en la segunda mitad de la década de los ochenta constituyen ejemplos de esa capacidad de acción que minimiza el costo hasta donde es posible. Para ser justos hay que señalar que cuando Ross y Büchi toman el timón gran parte del precio está pagado, y en cambio Cauas y De Castro tuvieron la ingrata tarea de decirle a la población que todavía había más precio que pagar.

Existen otros dos matices que se deben añadir. El primero es que no soy economista, y Chile siempre ha estado lleno de no economistas que pontifican sobre economía. Acepto lo limitado de mi observación, pero añado que las explicaciones que han dado los economistas no responden a estas preguntas. Por ejemplo, en torno a la crisis de 1982 De Castro sigue defendiendo el dólar a 39 pesos y atribuye la crisis a la falta de flexibilidad de los salarios (responsabiliza especialmente a José Piñera), aunque las dos razones (dólar fijo y rigidez de los salarios) están en niveles diferentes, y en situaciones así no hay cómo impedir una baja en los salarios. En el caso de la fijación del dólar, aunque De Castro, como lo señalan muchos economistas, da argumentos muy sólidos, existen numerosos ejemplos históricos de que los cambios fijos no pueden mantenerse una vez que se desatan contra ellos no sólo fuerzas económicas sino también políticas y emocionales. Para no hablar del caso argentino podemos mencionar la Francia de después de De Gaulle, o la devaluación del dólar llevada a cabo por Richard Nixon en 1971, dos situaciones muy moderadas por lo demás. El segundo matiz que hay que añadir al juicio acerca de las carencias en economía política es que de haber llevado a cabo una estrategia que hubiera limitado el daño y la recesión en ambos casos, 1975 y 1982, y la caída hubiera llegado, supongamos, a un 6\%, ya que era impensable que no se tuviera que pagar un precio, de todas maneras consideraríamos que fueron, cada caso, una catástrofe después de la depresión de los treinta, ya que no tendríamos otro punto de referencia.

Especialmente respecto a 1982 hay un elemento adicional para sostener que pudo aminorarse el sacrificio. La recuperación fue bastante rápida y 
luego abrió paso al período más largo e intenso de crecimiento de la historia chilena, al menos desde que hay cifras confiables. Esto querría decir que las cosas no estaban tan mal en la antesala de la crisis, en el primer semestre de 1981. Mientras que en 1975 había un pasado de acumulación forzosa de crisis, no fue así seis años después. Algo se hizo mal o se dejó de hacer. También valga como comparación el caso argentino. La asombrosa recuperación a partir del 2003 no se debe a que la administración Kirchner tenía la "verdadera receta", sino a que las cosas tampoco estaban tan mal, pienso, a fines de los noventa. Algo se hizo muy mal o se dejó de hacer.

\section{Los economistas y la dictadura}

Este libro entrega muchos antecedentes acerca de la relación entre los economistas y el régimen militar, un cuadro complejo del cual es muy fácil hacer una caricatura, lo que en general se ha hecho. Es cierto que el programa pudo desarrollarse gracias al apoyo en primer lugar del régimen y en segundo lugar directamente de Pinochet. Por otra parte, si en sus grandes líneas es la base de nuestro Chile actual y, con uno u otro pequeño matiz, sobre todo cambiando palabras, casi todos lo han llegado a asumir como razonable, no puede ser considerado como una simple criatura del “despotismo de Pinochet” o "hijo de la dictadura”. Esto dice relación con la experiencia histórica de las dictaduras de desarrollo, que en el siglo XX han tendido a dar paso de una manera relativamente natural a regímenes más liberales.

Sin embargo lo dicho no resuelve otro tema, que es el del apoyo de la derecha al régimen militar. Aunque no hay que olvidar que también la Democracia Cristiana en cierta medida lo apoyó al comienzo, y que la Unidad Popular, por otro lado, tenía como modelo a los sistemas marxistas, archidictaduras por decir lo menos. Sergio de Castro y sus pares pertenecían a la derecha, pero no eran la derecha. Eran parte del alma más moderna y a la vez tecnócrata de la misma, con el toque nihilista de estos casos de creencias supremas en la organización. Si lo interpretamos en este sentido, parece que tendría razón Julio Chaná cuando les reprochaba su agnosticismo, si confiamos en el testimonio del Padre Roger Veckemans (p. 97). (Esto nada quiere decir acerca de sentimientos y creencias íntimas de Sergio de Castro; a partir de este libro no se podría afirmar nada al respecto.) De algunos de estos economistas se puede tener la impresión de que si Stalin hubiese resucitado y les hubiera ofrecido la dirección de un plan quinquenal, ellos habrían sopesado si la oferta era o no "interesante", pero en 
ningún caso que para eso habría sido necesario aplicar un criterio político o moral. De algunos empresarios actuales da la misma impresión.

Esto no es responsabilidad personal de De Castro, era parte de la reacción de un amplio sector de chilenos y chilenas y de la casi totalidad de la derecha que participaban del hastío de la extrema politización y de la odiosidad imparable en que se había convertido la vida cotidiana durante la Unidad Popular. El error moral de la derecha fue haber traducido lo que era una explicable reacción ante los acontecimientos y una voluntad legítima de participar en una reestructuración (limitada, eso sí) de la organización del Estado y de los mecanismos económicos en una actitud de renuncia a valores políticos y morales, como si ese aspecto de la vida hubiera desaparecido del horizonte.

Es cierto que había esa preocupación al menos tras la crisis política internacional de 1978. El mismo De Castro habla acerca de los planes políticos de Hernán Cubillos, por un momento el motor para una reforma del régimen militar, una convergencia con el "modelo occidental”, es decir una democracia representativa. El mismo Jorge Alessandri, que en varios momentos también mostró esa actitud, desde el Consejo de Estado intentó convencer a la Junta de que era necesario diseñar una estrategia de regreso a la democracia, antes de lo que efectivamente ocurrió. Sin embargo la imagen de que la inacción de la derecha contribuyó al desborde de organismos como la DINA sigue constituyendo un problema para sus herederos políticos en la primera década del siglo XXI, y parece que cada día este tema se hace más intenso. En estos momentos la llamada centroderecha cree que ignorando la necesidad de tener una interpretación de la historia va a convertir en innecesaria a la historia. Hasta el momento se pisa la cola.

En los años setenta los “Chicago” y sus defensores insistían mucho que ellos estaban construyendo las bases de una "sociedad libre”. En el ámbito económico se escuchan todavía muchos ecos de este discurso, que identifica "ser libre” con capacidad económica de gestión, de autosuficiencia. A veces con un tono de arrogancia se deja caer la sospecha de servilismo sobre todos los que viven de un sueldo. En el libro, De Castro no pierde mucho tiempo en justificar su política como defensa de la “libertad”. El problema sin embargo es central para evaluar este testimonio. En su época, entre 1974 y 1980, la defensa de la libertad económica provocaba burlas. Primero, porque parecía una especie de materialismo histórico liberal, algo nada de raro en el liberalismo económico y en la "cultura tecnocrática”. Segundo, lo más obvio, porque el programa económico se desarrollaba gracias al apoyo de un régimen militar, una dictadura en suma, en los años de la Dina. De esta contradicción muy pocos han dado una explicación convin- 
cente. Efectivamente, se trata del "pecado original" de la "experiencia chilena"10. La única defensa que se ha esgrimido parte del supuesto de que la libertad económica da paso a la libertad política.

La noción de "libertad" no es aproblemática. Precisamente por ahí parten los problemas. Existen diversos tipos de libertad, la política, la espiritual, la de la vida privada. También, como lo dijo el mismo Berlin, está la "libertad positiva" y la "libertad negativa". Ha habido bastante experiencia en el siglo XX de convivencia entre un sistema autoritario y una cierta libertad económica (que incluye propiedad privada), incluso en la Alemania nazi. La libertad de emprendimiento, tan cara al corazón de los neoclásicos, en términos numéricos sólo puede ser experiencia de muy pocos. No existe ley de causa-efecto entre libertad económica y libertad política, entendiendo por esta última la vigencia del Estado de derecho y la democracia moderna.

Sin embargo, no es que no haya ninguna relación. En primer lugar, en cinco mil años de historia de las "sociedades complejas", la libertad política ha sido una planta exótica. Sólo desde hace poco más de doscientos años se la tiene como valor supremo, y todavía hoy sigue siendo una minoría de los países del planeta. La democracia (con libertad) no es como un tesoro que se des-cubra, sino que es un proceso de construcción que no tiene nada de instantáneo. Por ello, la convivencia de un orden autoritario con economías de mercado y libertad relativa en lo económico ha sido un fenómeno recurrente. Una sociedad económica fuerte, en donde el comercio ha jugado un papel destacado, no es algo significativo sólo para una ínfima minoría. Porque para la libertad económica es fundamental que haya una cierta multiplicidad de esferas, de autonomías dentro de la sociedad, como también requiere de reglas del juego más o menos constantes más allá de caprichos políticos. Para afirmarlo a la inversa, no ha surgido una democracia que pueda pervivir si no está vinculada a una economía de mercado y a una cierta realidad internacional. No hay ley de causa-efecto; hay vinculación, cercanía, coexistencia. Lo mismo se da entre las grandes creaciones políticas y sociales y aquellas realidades de la cultura, Atenas, Florencia, París. El desarrollo económico no crea la cultura, pero ésta, cuando alcanza a distinguir a una sociedad, nunca está muy lejos de la economía de mercado, con propiedad privada, intercambio, alguna libertad y seguridad de desplazamiento.

Estas consideraciones no salvan del todo al caso chileno, pero lo colocan en un contexto adecuado. Un lapsus autoritario no es un pecado en la historia, si se conserva la orientación hacia el "modelo occidental”. Pero

${ }^{10}$ Arturo Fontaine Talavera, "El Pecado Original de la Experiencia Capitalista Chilena”, 1992. 
sí fue pecado haber prescindido de la orientación hacia valores políticos en un sentido amplio, de haberlos hecho carne de la realidad mental. Algo de esto, un "algo" quizás decisivo en lo moral, hubiera moderado las cosas. No se puede negar que con el gabinete del cual Hernán Cubillos era el alma a partir de abril de 1978 las cosas comenzaron a cambiar.

\section{Economía y la posibilidad del desarrollo}

En los últimos años los líderes de la Concertación, que hacia 1990 asumieron la herencia de la modernización económica del gobierno militar, han atribuido a estos "otros diecisiete años" la totalidad del avance económico y social. Un reciente artículo en The New York Times parece santificar esta versión a nivel internacional ${ }^{11}$. En 1990 se decía que a una excelente estrategia económica se le unía la democracia política; estas dos partes hacían el "modelo chileno". Hoy día la Concertación asegura que todo se debe a que la democracia ha permitido la inserción internacional de Chile y se ha podido aprovechar bien la dinámica de la "globalización”. Y que a ciertas reformas estructurales ejecutadas por los "Chicago Boys", que cada día reconocen menos, se les ha agregado un verdadero contenido social. Existe una oposición extraparlamentaria de una fuerza sorda en el mundo cultural, que considera que todo está malo, pésimo. De creer estas últimas afirmaciones, estaríamos viviendo una suerte de fin de mundo, y estaríamos en la peor fase de la historia republicana del país. ¿Se cree sinceramente en esto o es una afectación de época? Un argumento que se esgrime a favor de la tesis de la Concertación, tal como se indicó, es comparar el crecimiento del 73 al 90 con el que viene después. Si se consideran las crisis de 1975 y 1982 el resultado favorece claramente a la Concertación.

Se trata evidentemente de un artilugio de cifras. A partir de 1987 va a existir un período extraordinario por diez años; después de 1998 uno más ordinario, pero considerablemente mejor que la historia de antes de 1973. En líneas generales la Concertación ha desarrollado creativamente la economía política heredada del régimen de Pinochet, y ha presidido el Chile más próspero y pacífico de todo el período que parte, por dar una fecha, en 1900. Esto no quita que si desde 1990 hasta el 2007 el producto se ha triplicado, es obvio que al menos los recursos del Estado en términos reales también

${ }^{11}$ David Rieff, “After the Caudillo”, The New York Times Magazine, 18 de abril de 2007. Rieff, hijo de Susan Sontag, insinúa además que Allende fue muerto por los militares, y nada dice de la orientación de la Presidenta Bachelet hasta 1989 y hacia el modelo de la antigua Alemania Oriental. 
se han triplicado, y por lo tanto hay mucho más que dar. Se nota en el gasto social, en las obras públicas, y también en mucho derroche por ahí y por allá. Todo viene del tronco de haber vinculado al país a la dinámica de la economía mundial, que es la principal tesis que defendieron los "Chicago Boys” desde poco después de la firma del Convenio de 1955.

La economía política, donde se encuentran las instituciones públicas con el proceso económico, no es algo tan simple como aquello de entender bien la teoría y saber ponerla en ejecución. Con todo, Chile ha dado un salto cualitativo notable en su modernización económica y social. Se ha eliminado la inflación; el desempleo logró bajarse desde fines de los ochenta; se ha diversificado en cierto grado la capacidad exportadora, sobre todo en recursos naturales renovables, y desde 1986 no se ha tenido que mendigar en las instituciones financieras internacionales. Ha crecido la clase media, de definición siempre compleja.

Chile, sin embargo, no es un país desarrollado donde podamos decir que la mayoría sustancial de la población pertenece a una clase media con el nivel educacional comparable al de sociedades de este tipo. Razones de economía política, de cultura económica, de liderazgo y también de estado de ánimo pueden incidir en esta falencia, y no podemos asegurar que alguna vez estaremos en esas condiciones. En estas tres décadas la población ha internalizado algunos sanos principios de economía política, por ejemplo, que no se puede gastar indefinidamente y quizás una mayoría aceptaría lo que tanto predicó Jorge Alessandri, que el aumento de los ingresos tiene que estar relacionado con el aumento del producto.

La competencia política es una taza de leche aunque la convivencia social cotidiana refleje muchas veces una primitivización de las relaciones sociales. Es cierto que en treinta y cuatro años el país ha experimentado un cambio que a muchos parece fenomenal, pero si comparamos el país de 1973 con el de treinta y siete años antes, es decir, 1936, es claro que cualquier observador puede ver cambios positivos por doquier. La sensatez política debería ordenar que nadie se entusiasme ni en alabanzas desmesuradas ni en la crítica destructiva. Chile, mejor en muchos sentidos, sigue siendo Chile.

Muchos críticos del Chile actual, de esa parte que heredó la imponente construcción de la cual De Castro y los suyos fueron los principales arquitectos, piensan que a esta etapa va a seguir una nueva, un agotamiento del mercado. La América Latina de nuestros días, que es parte de nuestra cultura, muestra a muchos actores nostálgicos de las "economías de comando" y hasta de los sistemas marxistas. En una crítica común a los "Chicago Boys”, y no sólo de economistas de oposición al régimen sino que de 
sectores del mismo gobierno, se los acusaba de ser meros ideólogos que querían vender un recetario universal al modo de ingenuos propagandistas de una Ilustración barata. No faltan algunos motivos para apoyar estos juicios: el aire forzado de ciencia absoluta con que defendían sus medidas; los resultados a corto plazo, tan contrarios a las predicciones que se hacían (esto es muy cierto hacia 1975); que la reforma económica fuese acompañada de un lenguaje que quería llevar la razón económica a todos los rincones de la vida, aunque esto sería en parte asumido después también por el mundo de la Concertación.

Aquí se propone otra perspectiva para comprender nuestro presente. La reforma económica no fue parte de un proyecto "pretoriano-capitalista”, “de hegemonía de una clase”, sino que procedió de una crítica a las tendencias que se fueron imponiendo a partir de la década de 1930. Lejos de representar un fenómeno aislado del mundo, respondió a unos de los debates públicos más clave de la historia política del mundo moderno, ¿hasta qué punto se puede intervenir la economía?

La moderna economía de mercado no ha sido una etapa de lo moderno, sino que su punto de referencia más poderoso es la producción y reproducción material. Pero aun cuando se trata de un fenómeno poco querido por su cultura, porque estaría escaso de “lo humano”, ha permitido que por primera vez a lo largo de cinco mil años de historia una mayoría sustancial de la población de algunas sociedades haya abandonado el estado de "pobreza”. Desde luego lo que es pobreza va siendo constantemente definido por la experiencia histórica, así como lo material aparece como lo más apetecido por el ser humano, aunque éste nunca queda satisfecho. Esto es lo que comúnmente se ha llamado las “contradicciones del capitalismo democrático”.

¿Es el capitalismo un fenómeno de la sociedad moderna que perecerá con ella? Nadie tiene el monopolio para poder afirmar taxativamente cuándo termina lo moderno. A medida que se estudian las civilizaciones que han existido en la historia, al investigador inmediatamente le asoma una realidad $\mathrm{y}$ es que el intercambio en base a una multitud de actores, vale decir la producción y el comercio, ha sido un constituyente fundamental de cada una de ellas. Si esto ha sido así quiere decir que lo que se llama mercado, que también se puede denominar "sociedad civil económica”, ha existido siempre, aunque con variados grados de autonomía frente a lo político. Lo que añade la civilización moderna es en primer lugar algo cuantitativo, un mercado más grande, en su tendencia “globalizado” a partir del 1500. En segundo lugar le añadió una razón abstracta, el factor financiero, que comienza a desarrollarse en torno al mismo 1500, y que incluye lo que para 
algunos todavía es un escándalo, que el dinero crea dinero. En tercer lugar, la revolución industrial y la vinculación entre ciencia y técnica.

Este mundo económico nuevo será el corazón de la sociedad moderna, de la democracia liberal. A partir de este "modelo occidental" existen alternativas, los modelos colectivistas, que incluyen economía de comando y monopolio del poder por parte del Estado-partido. Y ha existido un viejo sueño de la política moderna, una realidad intermedia. Aunque los sistemas totalitarios pudieron haber triunfado política y militarmente (y no desconocieron el tema del incentivo personal, incluso en los campos de exterminio), el sistema más fuerte ha estado constituido por la economía de mercado que incluye la sociedad civil económica, casi siempre inserta en una democracia más o menos liberal. Esta síntesis no puede ser definida con exactitud, y mientras exista la discusión pública acerca del deber ser en la sociedad, habrá siempre en la frontera un margen de movimiento entre lo que hace la sociedad civil económica y lo que puede hacer la sociedad como un todo a través del Estado y de sus instituciones. Mas en la complejidad social moderna existe un mínimo común denominador para el desarrollo del mercado. Toda la saga de los "Chicago Boys", con sus luces y sombras, fue parte de esta política de converger en torno a este mínimo como base para la adaptación de Chile en su indispensable interacción con el mundo, y para la plenitud social posible. Sus logros no son nada de pequeños.

\section{BIBLIOGRAFÍA}

Berlin, Isaiah: "Political Judgement”. En Isaiah Berlin, The Sense of Reality. Studies in Ideas and their History. Nueva York: Farrar, Straus \& Giroux, 1996.

El Ladrillo. Bases de la Política Económica del Gobierno Militar Chileno. Santiago: Centro de Estudios Públicos, 1992.

Fontaine Aldunate, Arturo: Los Economistas y el Presidente Pinochet. Santiago: Zig-Zag, 1988.

Fontaine Talavera, Arturo: "El Pecado Original de la Transformación Capitalista Chilena”. En Barry B. Levine (ed.), El Desafío Neoliberal. El Fin del Tercermundismo en América Latina. Bogotá: Ed. Norma, 1992.

Ghersi, Enrique: “El Mito del Neoliberalismo”. En Estudios Públicos, 95 (2004).

Góngora, Mario: Ensayo Histórico sobre la Noción de Estado en Chile en los Siglos XIX y XX. Santiago: Universitaria, 2006; original, 1981.

Harberger, Arnold: “Memorandum sobre la Economía Chilena”. En Estudios Públicos, 77, 2000.

Soto, Ángel: El Mercurio y la Difusión del Pensamiento Político-Económico Liberal 19551970. Santiago: Centro de Estudios Bicentenario, 2003.

Rieff, David: “After de Caudillo". En The New York Times Magazine, 18 de noviembre de 2007. 
Valdés, Juan Gabriel: La Escuela de Chicago: Operación Chile. Buenos Aires: Grupo Editorial Zeta, 1989.

Vial Correa, Gonzalo: Una Trascendental Experiencia Académica. Santiago: Facultad de Ciencias Económicas y Administrativas; Pontificia Universidad Católica de Chile, 1999. 